Nloma 2016, 34(1), 71-80

Revista de Psicologia, Ciències de l'Educació i de l'Esport

ISSN: $1138-3194$

Copyright (c) 2016

www.revistaaloma.net

\title{
Introducción del sistema PECS para la superación de las limitaciones comunicativas en un caso de síndrome de West
}

\author{
José Peirats-Chacón \& $\mathrm{M}^{\mathrm{a}}$ Isabel Vidal-Esteve \\ Universitat de València
}

Recibido: 26-11-2015

Aceptado: 18-3-2016

\begin{abstract}
Introducción del sistema PECS para la superación de las limitaciones comunicativas en un caso de síndrome de West

Resumen. En este estudio de caso se aborda la intervención realizada en una alumna de cuatro años, escolarizada en un aula específica de un centro ordinario, y a la que recientemente han diagnosticado síndrome de West. Aplicando, a lo largo de un trimestre en un aula de Audición y Lenguaje, el sistema de comunicación por intercambio de imágenes (PECS) se pretende superar las graves limitaciones comunicativas de la alumna. El procedimiento metodológico utilizado es mixto y las técnicas de investigación empleadas son la aplicación de test estandarizados, la entrevista, los cuestionarios, los registros de observaciones y el análisis documental. A partir del test que establece la evaluación inicial del caso, se aplica el programa y se registran diariamente los datos, además de entrevistar a la familia y analizar la documentación y los cuestionarios cumplimentados por el profesorado implicado. Los resultados obtenidos muestran que las reticencias de parte del profesorado inciden en la necesaria coordinación, pero no son un obstáculo para que la alumna alcance ciertos beneficios en cuanto a las relaciones de interacción, petición y contacto visual, aspectos fundamentales para lograr la comunicación.
\end{abstract}

Palabras clave: síndrome de West; sistema de comunicación alternativo; PECS; intercambio de imágenes; intervención en comunicación

Introducing PECS to overcome the communicative limitations in a case of West syndrome

Summary. This case study tackles the intervention in a four year-old student schooled in a specific class at an ordinary school who was recently diagnosed with West syndrome. Applying during a quarter in a Hearing and Speech classroom The Picture Exchange Communication System (PECS) was applied over a period of an academic quarter in the school's Hearing and Speech classroom with the goal of helping the student overcome the serious communicative limitations associated with the syndrome. A mixed methodological procedure is used, with research techniques consisting of the application of standardized tests, interviews, questionnaires, observations, records and document analysis. From the initial assessment of the case, established by the test, the program is implemented and data are recorded daily, in addition to interviewing the family and analysing documents and questionnaires filled out by the teachers involved. The results show that while the reluctance of some teachers suggests the need to improve coordination, this wasn't an obstacle to the achievement of certain benefits in terms of student interaction, request and eye contact, essential for communicative achievement.

Key words: West syndrome; alternative communication system; PECS; picture exchange; communicative intervention

Correspondencia José Peirats-Chacón

Didàctica i Organització Escolar

Blasco Ibáñez, 30 - 46010 València

Tel. 963864592

Email: Jose.Peirats@uv.es 


\section{Introducción}

El síndrome de West (SW) es una encefalopatía, caracterizada principalmente por espasmos epilépticos. En este trabajo que presentamos nos vamos a ocupar de un estudio de caso, el de una niña de cuatro años al que recientemente le han diagnosticado ese síndrome (febrero de 2015).

Los niños con SW presentan severos problemas de comunicación, el que nos ocupa: ausencia total de habla, así como de intención comunicativa. Este hecho supone que las personas que se encuentran a su alrededor (familiares, docentes...) tienen dificultades para saber qué necesidades presentan en cada momento. A esta situación se añaden las escasas expectativas que sobre el síndrome tienen tanto los médicos como el profesorado, pues muchos de ellos suponen que difícilmente se comunicarán algún día y que lo mejor es ir viviendo el día a día. Si los propios profesionales no conciben las posibilidades de comunicación que existen en estos niños y niñas, ya sea porque las desconocen o porque no confían en ellas, las esperanzas de las familias se reducen y las capacidades del alumnado se ven mermadas por falta de actitud y de estimulación.

Frecuentemente, los niños y las niñas con un desarrollo típico, a partir de los seis meses, comienzan a desarrollar la comunicación intencional realizando sonidos diversos semejantes a los de su lengua materna y recibiendo, a cambio, refuerzos sociales y tangibles. Así pues, tal y como señalan Frost y Bondy (2002), adquieren habilidades comunicativas sin tener que trabajar de forma sistemática o específica el lenguaje, ya que lo hacen mediante intervenciones con otros modelos de lenguaje más desarrollados (Halle, 1984). Sin embargo, hay algunos que no presentan este tipo de desarrollo, como es el caso de los niños y las niñas con trastorno del espectro autista, quienes no sienten reforzada su comunicación.

Ante esta situación, deberemos desarrollar un plan para enseñarles lenguaje activamente (Frost \& Bondy, 2002) y, con el fin de lograrlo, será necesario crear oportunidades comunicativas para favorecer situaciones en las que el alumnado muestre operaciones de establecimiento (establishing operation). Es decir, momentos en los que manifieste un deseo por conseguir algo y nosotros seamos el medio para obtenerlo (Michael, 1983). Para ello se requiere el uso de la comunicación aumentativa y/o alternativa (SAAC) que, según Basil (2001), es un ámbito interdisciplinar que abarca un extenso conjunto de elaboraciones teóricas, sistemas de signos, ayudas técnicas y estrategias de intervención que se dirigen a sustituir y/o aumentar el habla. Esta se implementa a través de sistemas para impulsar, complementar o suplir el lenguaje oral mediante el uso de objetos, fotografías, dibujos, signos, o símbolos (Fuentes-Biggi et al., 2006).

Entre los distintos sistemas destacamos PECS (Picture Exchange Communication System ${ }^{\circledR}$ ), reconocido a escala mundial por centrarse en el componente de la iniciación a la comunicación, y desarrollado por Bon- dy y Frost en 1994 con el fin de ayudar a las personas con autismo en la adquisición de destrezas para la comunicación funcional. Según sus autores, se articula, a través de una serie de fases, en torno al intercambio de imágenes entre el individuo y las personas de su entorno, y consiste en coger una figura plastificada de un panel y entregarlo al adulto, solicitándole un objeto real a cambio. El protocolo para su uso se basa en el libro Conducta verbal, de Skinner, ya que se enseñan sistemáticamente las operaciones verbales usando métodos de ayuda y reforzamiento para finalmente lograr una comunicación independiente. Actualmente, se utiliza como un método interactivo de comunicación, con tal nivel de flexibilidad que es útil para casi cualquier individuo no verbal, por lo que es de los más difundidos y empleados. A lo que añadimos que no se utiliza de manera aislada, sino que sirve para adquirir otros sistemas de comunicación, incluso el lenguaje.

Sin embargo, entre todos los casos encontrados no ha aparecido ninguno en el que el sistema haya sido utilizado, con éxito o sin él, en alumnado afectado por el SW. A pesar de ello, son suficientes y significativas las semejanzas que se han podido encontrar en aspectos concretos, principalmente en el ámbito de la comunicación con el trastorno del espectro autista (TEA) y con el síndrome de Angelman en los que sí se usa y está siendo útil el sistema PECS. De hecho, tal y como apuntan Chkout, Sarduy, Tunas y Leyva (2011, p. 11): «los rasgos que se describen en el espectro autista no se producen solo en sujetos con trastornos profundos del desarrollo, sino en otros que reciben otros diagnósticos (...), por ejemplo epilepsias de la primera infancia que se acompañan de retraso mental (como el SW)».

Para entender la relación entre el TEA y el SW y poder justificar el uso del sistema PECS en el caso, es necesario remontarnos a los orígenes y la evolución del primero. Leo Kanner, el psiquiatra infantil austriaco que describió el autismo, detalló la afección en once casos, uno de los cuales presentaba epilepsia. Más adelante, en 1972 se revisaron los hallazgos de estos pacientes y dos de ellos mostraban ataques epilépticos. Así pues, se establece una relación entre el autismo y la epilepsia; el 25\% de las personas con TEA presentarán epilepsia en algún momento de su vida (Bolton, Carcani-Rathwell, Hutton, Goode, Howlin \& Rutter, 2011). Por su parte, otra característica, no menos importante, son las regresiones autísticas aparentemente relacionadas con la epilepsia, principalmente si existe discapacidad intelectual (Sansa et al., 2011). Y es que, en los síndromes genéticos que presentan epilepsia, en las alteraciones corticales con espasmos epilépticos y en los síndromes epilépticos con bases genéticas (en los que se podría clasificar el Angelman) se describe el autismo como parte o consecuencia del deterioro epiléptico (Arberas, 2011). En consecuencia podemos señalar, tal y como apunta el mismo autor, que el SW es una encefalopatía epiléptica con alto riesgo de desarrollar autismo.

Centrándonos en el ámbito de la comunicación, comúnmente las personas con TEA o síndrome de 
Angelman, al igual que los que presentan SW, tratan de comunicarse como sus capacidades les permiten; empujando a la persona hacia el objeto preferido o lanzando lejos objetos no deseados. Aun así, existen ocasiones en las que no logran la comunicación efectiva y recurren a las conductas disruptivas. Es por ello por lo que debemos presentarles otros medios, diferentes o complementarios al lenguaje, que les permitan expresarse y que lleguen a evitar o disminuir problemas de conducta por frustración. Es aquí donde la introducción de un SAAC de forma temprana sería fundamental (Díaz-Caneja, 2013).

En estos síndromes, las dificultades motrices y su peculiar modo de comunicarse, así como los escasos tiempos en los que mantienen su atención, dificultan en gran medida el aprendizaje de signos, razón por la que se suele descartar dicho sistema. Asimismo, pese a que se ha demostrado que el uso de imágenes o pictogramas es también limitado (Calculator, 2004), otros señalan que está resultando efectivo con estos niños el uso combinado de imágenes mediante el sistema PECS y diversos dispositivos electrónicos (Díaz-Caneja, 2013).

Ahora bien, el SW, clasificado como una enfermedad rara, no ha sido objeto de numerosos estudios o investigaciones, motivo por el cual la información disponible es insuficiente e imprecisa, sobre todo en lo que a intervención se refiere. En Europa, según Forman et al. (2012), se considera «rara» una enfermedad que afecta a 1 de cada 2.000 personas. El que nos ocupa afecta a 1 de cada 5.000 nacidos vivos (Campistol \& GarcíaCazorla, 2003) y se trata concretamente de una encefalopatía epiléptica dependiente de la edad que predomina en el sexo masculino y se caracteriza por la presencia de al menos dos de los aspectos de la tríada electroclínica: espasmos epilépticos, retardo en el desarrollo psicomotor y patrón encefalográfico de hipsarritmia (Pozo, Pozo \& Pozo, 2002).

El rasgo más característico del SW son las crisis de espasmos epilépticos, descritas por West en 1841. Estas producen una alteración momentánea del funcionamiento cerebral, debida a la descarga súbita y desproporcionada de los impulsos eléctricos que habitualmente utilizan las células del cerebro (Aguirre, Angulo, Guerrero, Motero \& Prieto, 2008). Sus mioclonías normalmente consisten en la contracción brusca (de flexión, extensión o mixto), generalmente bilateral y simétrica de todos los músculos del cuello, tronco y miembros, acompañada de la pérdida de la conciencia (Pozo et al., 2002). Entre los factores que pueden precipitar estos espasmos se encuentran los ruidos repentinos, la estimulación táctil, el hambre, la excitación y el calor ambiental. Cuando se producen las crisis epilépticas, principalmente las más fuertes, estas suelen ocasionar, a largo plazo, regresiones, hipotonía y deterioro psicomotor: pérdida de seguimiento visual y de la prensión -ambas características bastante importantes para el trabajo sobre su comunicación mediante PECS(Atuesta, Reina Lozano \& Gélvez, 2009).

Basándonos en la etiología del SW se han conside- rado clásicamente tres formas: idiopáticas, criptogénicas y sintomáticas, la última de las cuales es la más frecuentes -en el 80\% de los casos- (Campistol \& García-Cazorla, 2003) y la que peor pronóstico tiene (Pozo et al., 2002). Además, tal y como afirman dichos autores, esta se inicia en la mayoría de los pacientes (86.8\%) en el primer año de vida y tiene un pronóstico grave, ya que en el $90 \%$ de los casos ocurre el retraso mental (Atuesta et al., 2009). Entre las manifestaciones clínicas que presentan se observa la sonrisa, la risa y la expresión facial confusa o asustada, posiblemente relacionadas con lesiones cerebrales orgánicas; y el llanto y la somnolencia tras los espasmos.

Para la intervención en la comunicación de niños con SW necesitamos conocer cuál es el grado de deterioro cognitivo que estos presentan. Normalmente, la afectación cognitiva suele ser frecuente debido a que la epilepsia influye en el proceso de maduración normal del individuo. Así pues, será ineludible tener en cuenta la frecuencia de las convulsiones, la etiología de las mismas, su duración y los efectos secundarios que provocan los fármacos antiepilépticos (Toro, 2012). Una vez conocidos y valorados dichos aspectos sobre el caso, se requerirá, dentro de las posibilidades del mismo, un aumento progresivo de la intención comunicativa y del manejo de un código lingüístico útil y funcional que permita desarrollar tanto la representación y la comprensión como, principalmente, la expresión.

\section{Planteamiento metodológico}

Con el fin de abordar el síndrome comentado, se ha optado por una metodología mixta donde el investigador mezcla o combina técnicas de investigación, métodos, enfoques, conceptos o lenguaje cuantitativo o cualitativo en un solo estudio (Johnson \& Onwnegbuzie, 2004). Se trata de una investigación de campo, pues se basa, tal y como describe Sabino (1989), en informaciones obtenidas directamente de la realidad que nos permiten cerciorarnos de las condiciones reales en que se han conseguido los datos. Asimismo es descriptiva, ya que permite observar y especificar el funcionamiento del nuevo programa de comunicación que se va a implantar; y finalmente, se trata de un estudio de caso, pues nos centramos en la particularidad y la complejidad de un caso singular (Stake, 1998), como un sistema acotado por los límites que precisa el objeto de estudio pero enmarcado en el contexto global donde se produce.

\section{Objetivos}

En esta investigación se ha utilizado la metodología mencionada para abordar el siguiente objetivo general: introducir el sistema de comunicación por intercambio de imágenes PECS para superar las limitaciones comunicativas en un caso de síndrome de West. Para poder conseguirlo hemos planteado una serie de objetivos específicos que nos ayudan a desarrollar el proceso de trabajo, como son los siguientes: 
1. Observar y analizar los diferentes contextos de interacción comunicativa del caso.

2. Comprobar y verificar la presencia de los requisitos necesarios para la aplicación del sistema PECS.

3. Diseñar y aplicar una intervención de introducción de dicho sistema en el caso seleccionado.

\section{Método}

\section{Participantes}

Nos encontramos ante un estudio de caso simple y de diseño holístico que, según Yin (2003), es el que se desarrolla sobre un solo objeto y con una unidad de análisis. En este caso, la unidad en la que se ha llevado a cabo la investigación empírica es una niña de cuatro años diagnosticada, según su Informe neuropediátrico hospitalario (26/01/2015), de SW con epilepsia refractaria precisada hasta dicha fecha. Cumple dos de los ítems de la tríada electroclínica y presenta una media de dos episodios diarios de crisis epilépticas, consistentes en hipertonía de extremidades superiores con mirada perdida y desconexión del medio (llegando a la pérdida de conciencia y caída al suelo por 30-40 segundos) y retraso psicomotor caracterizado, entre otros, por la marcha atáxica con aumento de la base de sustentación.

La niña, según la solicitud de informe pedagógico y el posterior dictamen de escolarización, asiste desde el 27/03/13 a una unidad específica de Educación Especial implantada en un centro ordinario. En el último documento consta que presenta, según la clasificación de la OMS/DSM-IV, necesidades educativas especiales (NEE) permanentes derivadas de encefalopatía con retraso madurativo global y posible SW. Para su trabajo diario se le ha realizado una adaptación curricular individualizada significativa (ACIS) con nivel de dos años, según dicho documento todos los objetivos de los tres bloques de contenidos (conocimiento de sí mismo y autonomía personal, conocimiento de su entorno, y comunicación y representación) se encuentran en proceso de consecución, a excepción de «mostrar interés por explorar los elementos del entorno» e «identificar a algunos miembros de su familia» que ya se registran como conseguidos. Dispone para su atención de un fisioterapeuta (4 horas semanales), su tutora especialista en Pedagogía Terapéutica, una educadora y una maestra en Audición y Lenguaje (4 horas semanales). La familia se implica en su formación y tiene buena comunicación y relación con la escuela y el profesorado.

\section{Instrumentos}

El enfoque mixto combina, tal y como apuntan Pacheco y Blanco (2002), la utilización simultánea de fuentes de datos claramente identificados con los estilos de investigación cualitativo, tales como la entrevista realizada a los padres o diferentes registros observacionales llevados a cabo, con los instrumentos cuantitativos, como son los test estandarizados necesarios para establecer una línea base inicial y las encuestas cumplimentadas por diferentes miembros del profesorado directamente relacionado con la niña.

Además en la recogida de datos, cabe destacar que se han recopilado documentos personales como los ya mencionados (ACIS, informe, diagnóstico clínico, dictamen de escolarización) o registros audiovisuales (un compendio de grabaciones de vídeo con algunos de los hitos más significativos en el proceso). Asimismo, durante toda la intervención, se ha realizado un registro de observación parcialmente sistematizado (Sampieri, Collado, Lucio \& Pérez, 1998) por combinar lo anecdótico con las fichas de observación estandarizadas -adaptadas de Frost y Bondy (2002)-, ya que parece imprescindible para ir más allá de las meras verbalizaciones sobre el pensamiento o la conducta y detectar el reflejo en la práctica de las representaciones subjetivas (Evertson \& Merlin, 2008). En este caso se ha ido anotando, ensayo a ensayo, todo aquello percibido; cada mínimo logro conseguido por la niña en cada una de las fases trabajadas.

\section{Etapas de la investigación}

Tras la revisión inicial de la respectiva documentación (informes, ACIS, dictamen, etc.), se valoraron los distintos SAAC para seleccionar uno acorde a sus posibilidades. Una vez eliminada la gran mayoría, por dificultades cognitivas, motrices y de atención, se eligió PECS como método de partida para la intervención. Fue entonces cuando se empezaron a plantear una serie de objetivos específicos que facilitaran el proceso.

En la primera etapa, la prioridad fue establecer una línea base que permitiera conocer al máximo la situación actual de la niña, ya que es el reflejo de las conductas que se desean medir de forma previa a una intervención. Se utiliza en los diseños experimentales de caso único y empieza con la evaluación de la conducta del sujeto antes de su tratamiento (Martin \& Pear, 2008). Esta nos sería útil en gran medida para poder evaluar la propuesta en un futuro mediante una comparación de los resultados obtenidos en el inicio y en el fin de la misma. Para el establecimiento de la línea de base (LB) se contactó con la orientadora del centro, quien facilitó la documentación de la niña, el diagnóstico médico y una opción de test que contenía ítems que valoraban lo que más interesaba: su comunicación. Se trataba del inventario del desarrollo Battelle (Newborg, 2004), un test psicológico que evalúa las habilidades fundamentales del niño en las distintas áreas del desarrollo. A partir de algunos aspectos que en él se valoraban -las áreas que se consideraron más interesantes como la comunicación o la socialización-, de los requisitos básicos para la introducción de PECS y de una serie de características relacionadas con la socialización, la comunicación y el lenguaje, se diseñó un test con los ítems que se muestran en el anexo 1.

Siguiendo los principios de evaluación de Battelle se aplicó dicho test a la niña y se estableció una línea 


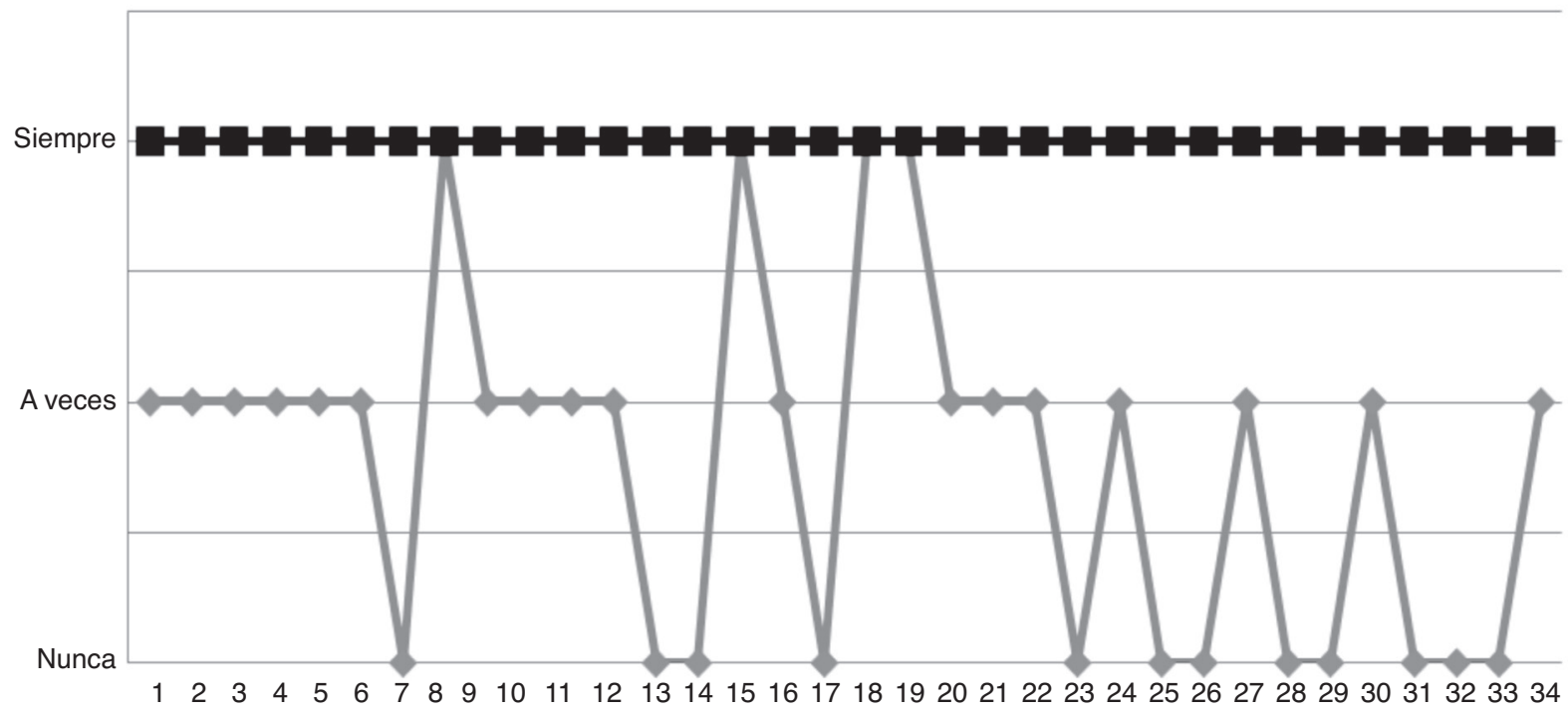

Figura 1. Gráfico de la línea base (LB), según los resultados del test inicial.

base (Figura 1); esta fue la línea de rombos mientras que la línea de cuadrados fueron las respuestas que corresponderían a un grupo normativo de unos 15 meses (basado en Bluma, Shearer, Frohman \& Hilliard, 1978).

En la segunda etapa, se consideró necesario el contacto con la familia con el fin de obtener la máxima información posible sobre la evolución que había tenido hasta el momento, sobre su diagnóstico y sobre la estimulación y tratamiento recibido en el ámbito educativo, ya que no era necesario conocer aspectos médicos ni farmacológicos. Como las entrevistas con los diferentes grupos que participan en la vida del caso tienen como objeto prioritario captar las representaciones e impresiones subjetivas, más o menos elaboradas de los participantes (Evertson \& Merlin, 2008), a los padres se les formuló una serie de preguntas básicas sobre el comportamiento de su hija desde el nacimiento.

Antes de la intervención, ante la situación de ausencia total de habla en la niña, se planteó la posibilidad de utilizar un sistema de comunicación alternativo, con el objetivo de que pudiera llegar a transmitir sus pensamientos, deseos o inquietudes de un modo u otro. Sin embargo, no era el único inconveniente, tampoco presentaba intención comunicativa, lo que dificultaba el proceso al no existir voluntad de petición. Era necesario, evidentemente, plantearse unos objetivos previos a la introducción del sistema que guiaran la tarea que había que realizar, tales como transmitir la idea de comunicación, crear un entorno propicio para la comunicación, y ser capaz de comunicarse a través de un sistema alternativo de comunicación, el PECS. En consecuencia, en una tercera etapa, se realizaron, en el aula de Audición y Lenguaje, junto con la especialista y durante un periodo de casi dos meses, una serie de actividades previas al uso del sistema seleccionado; entre ellas, desarrollar estrategias para facilitar la interacción, mantener el contacto visual, dirigir la mirada hacia ciertos objetos durante un cierto periodo de tiempo, asumir la conducta de señalar, despegar picto- gramas pegados con velcro, asignar significado comunicativo a las vocalizaciones espontáneas de la niña y reforzar las aproximaciones sucesivas, y también fomentar la espontaneidad en la petición para conseguir, finalmente, el uso del procedimiento de intercambio de imágenes.

Tras conseguir una serie de hitos necesarios (como la prensión del pictograma, la conducta de señalar: tocar señalando, señalar a distancia y la orientación de la mirada hacia el pictograma y hacia el objeto que se quiere conseguir) que posibilitaban el inicio se evaluaron los reforzadores, sin necesidad de un registro formal, con una encuesta de selección de vocabulario cumplimentada por los padres.

Una vez la niña estuvo preparada, en una última etapa se introdujo el sistema y se aplicaron, con ayuda de una segunda terapeuta, sus tres primeras fases para comprobar finalmente si se había respondido al objetivo planteado en la investigación, concretamente:

Fase I (intercambio físicamente asistido), cuyo objetivo es que el individuo, al ver un objeto altamente preferido, seleccione el símbolo de dicho objeto, se acerque al terapeuta y deje el símbolo en su mano.

Fase II (distancia y persistencia), pretende que el individuo acuda al tablero de comunicación, seleccione el símbolo, vuelva a su interlocutor y deje el símbolo en su mano.

Fase IIIA, que persigue la discriminación entre un icono preferido y un icono distractor.

Tras la realización de estas etapas se pasó un test, exactamente igual al inicial, que ha permitió contrastar ambos resultados y establecer una segunda línea posterior a la intervención que validara de forma visible la efectividad del proyecto (TICDI). Contrastar las perspectivas de los diversos agentes con las que se interpretan los acontecimientos es un procedimiento indispensable, tanto para clarificar las distorsiones y los sesgos subjetivos que necesariamente se producen en la representación de la vida cotidiana del aula, como para comprender el origen y proceso de formación de 
tales representaciones subjetivas, ofreciendo la posibilidad de admitir interpretaciones distintas y construir más críticamente el pensamiento y la acción (Evertson $\&$ Merlin, 2008). Con este fin se ha utilizado la triangulación de evaluadores en el test al ser aplicado por parte de distintos sujetos (educadora, tutora, maestra de Audición y Lenguaje y fisioterapeuta).

\section{Resultados}

Partiendo del objetivo general planteado desde un principio: introducir el sistema de comunicación por intercambio de imágenes PECS para superar las limitaciones comunicativas en un caso de síndrome de West, se muestran los siguientes resultados.

Estos se obtienen tras pasar el cuestionario sobre la comunicación y la interacción a los diferentes profesionales (TICDI) y compararlos con la línea base establecida al inicio mediante el mismo test (1ITC). Se ha realizado un análisis cuantitativo mediante el uso de gráficos lineales (Figura 2) que evidencia visualmente que se han producido cambios respecto al inicio, pero que estos no son valorados de manera uniforme desde las distintas perspectivas profesionales.

Analizando narrativamente el registro de forma cuantitativa, inicialmente la niña realizaba únicamente de forma constante (siempre) 4 de los ítems valorados. Asimismo, ejecutaba con asiduidad (a veces) 18 de ellos y no cumplía de ningún modo (nunca) 12. Pese a que-como después se detallará-cada miembro lo ha juzgado de una forma diferente, todos determinan que se han producido notables avances y en ningún caso se registra un retroceso.

En primer lugar, la maestra de Audición y Lenguaje considera, al igual que el fisioterapeuta, que siempre cumple 17 ítems (13 más que al inicio); a veces, 12 (el fisioterapeuta, 11); y nunca, 5 y 6 respectivamente ( 7 o 6 menos que al empezar). Por su parte, la tutora señala que son solo 7 los que efectúa de manera constante (3 más que antes de la intervención), 21 con cierta frecuencia y 6 nunca (6 menos que anteriormente).

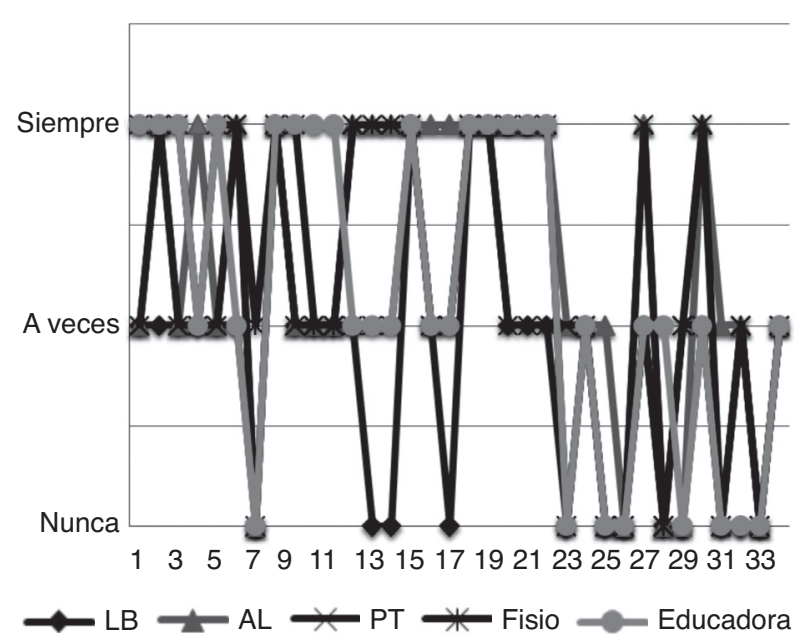

Figura 2. Resultados comparados de las respuestas al test por los distintos profesionales.
Finalmente, la educadora determina que siempre realiza 14 de los ítems valorados (10 más), en ocasiones 12 y no ejecuta 8 ( 4 menos que a priori).

Ahora bien, analizando cualitativamente aquellos datos más relevantes, se observa que se han logrado una serie de hitos que anteriormente no se cumplían. La mayor parte de estos están relacionados directamente con el sistema utilizado, como son: pinzar, mantener, mirar, arrancar, ofrecer y entregar correctamente un pictograma, pero a su vez, esta intervención ha conllevado la mejora de otros aspectos, como son la intención comunicativa, la sonrisa (ítems 2, 4, y 6), el contacto visual (ítems 9, 10 del test TICDI), la atención (ítems 30,33 y 34) o el reclamo de la atención a adultos (ítems 18-21).

Así pues, agrupando todos los resultados, podemos afirmar que en 10 de los ítems todos los profesionales coinciden plenamente en su decisión. Estos son: sonríe en respuesta a la atención de un adulto; extiende la mano hacia objetos que se le ofrecen; arranca un pictograma de la tira de velcro; gime o articula sonidos para reclamar la atención de un adulto, los cuales se producen ya de manera sistematizada; $y$ tiende objetos y los da al adulto; hace ademán de despedida; juega junto con otros niños; cuando se le dice «no» deja de hacer lo que está haciendo, que siguen produciéndose con la misma frecuencia que con anterioridad y que, por tanto, no ha mejorado.

Por otra parte, 9 de los 34 ítems valorados anteriormente no se producían en ninguna circunstancia y todos han mejorado, en menor o mayor grado, a juzgar por alguno de los evaluadores. Estos son: da palmaditas y tira de las facciones al adulto; mantiene un pictograma en la mano durante unos segundos; mira un pictograma durante unos segundos; da adecuadamente el pictograma a un adulto; hace uso del juego simbólico con los objetos; realiza imitaciones del adulto $\mathrm{u}$ otros; comparte objetos o juguetes cuando se le pide; repite sonidos que hacen otros; y repite la misma sílaba dos o tres veces ( $m a, m a, m a)$.

Finalmente, cabe destacar que 15 ítems ya se producían previamente pero tras la intervención todos ellos han mejorado en cierto grado. Los ítems son: observa a una persona que se mueve directamente dentro de su campo visual; gorjea en respuesta a la atención de otra persona; se mira las manos; sonríe o gorjea con frecuencia; sonríe en respuesta a los gestos faciales de otros; sonríe y gorjea al ver su imagen en un espejo; establece contacto visual; mantiene el contacto visual; busca el contacto visual; pinza un pictograma; ofrece el pictograma a un adulto; tira de un adulto para reclamar su atención; arrastra a un adulto hasta el objeto que quiere; manipula objetos y juguetes; hace ademán de dar besos y presta atención a música o cuentos.

Por otra parte, centrándonos en el análisis de los registros de observación llevados a cabo durante todo el proceso, se puede observar que los logros, pese al estancamiento inicial, han sido significativos día a día. El hecho de que consiga pinzar un pictograma (RO- 


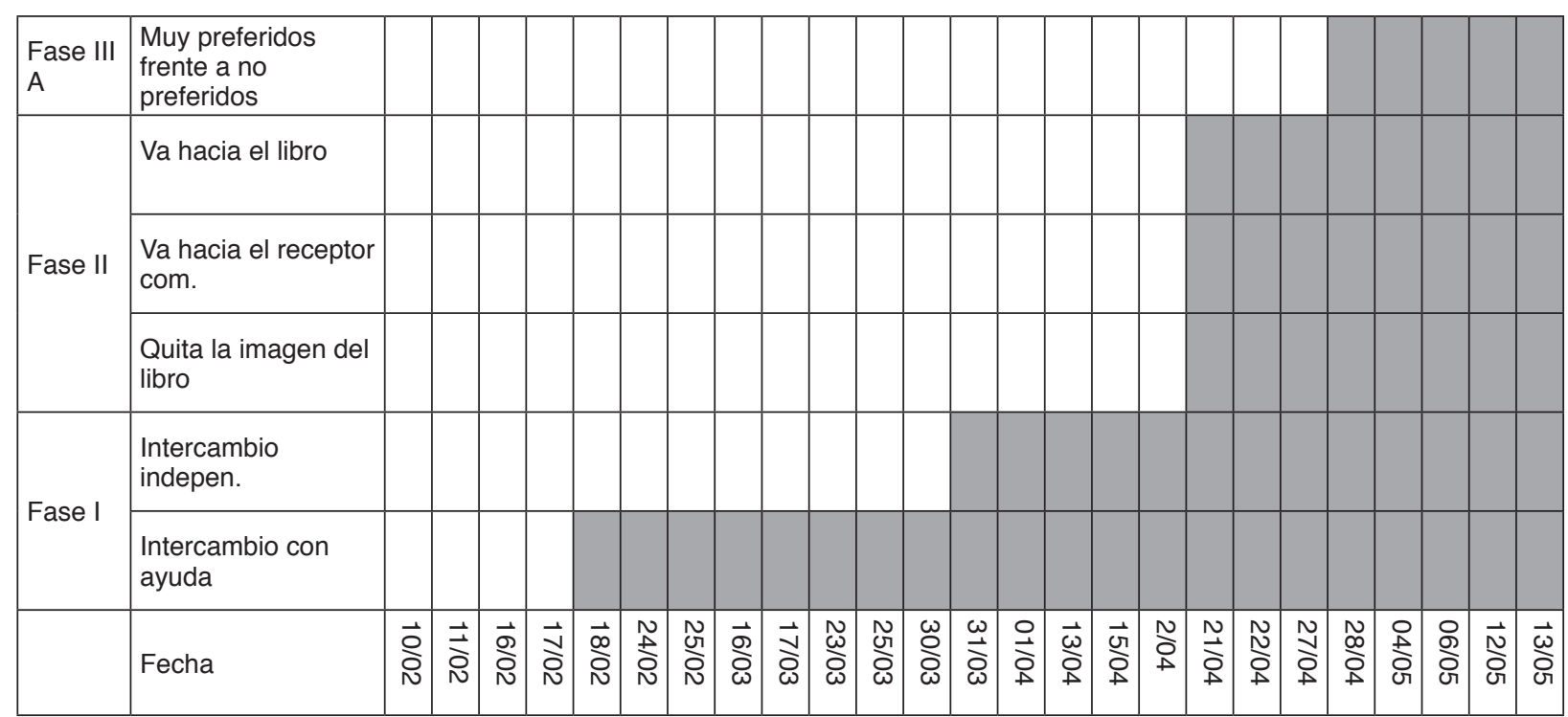

Figura 3. Gráfico de progreso a largo plazo de la intervención mediante PECS. Adaptado del Apéndice G del Registro de datos de Frost \& Bondy (2002).

FIIM2804) que al inicio era impensable sin la ayuda de un tapón (ROFI1802), de que recoja, alcance y entregue el pictograma de manera completamente autónoma (ROFI1504 y ROFI2004), incluso a una distancia de 4 metros (ROFII2704) o de que reclame la atención del adulto buscando el contacto visual (ROFIIM2704), prueban que sean más que evidentes los frutos de la intervención. Además, mediante el gráfico que se muestra a continuación (Figura 3), podemos valorar el proceso a largo plazo. A simple vista se observa que se tardó más de un mes en conseguir introducir la primera fase, pero la celeridad de adquisición de las siguientes fue superior.

Finalmente, en referencia a las palabras de la madre de la niña puede observarse cómo aprovechó la entrevista para apreciar los esfuerzos que se estaban llevando a cabo con su hija y también dar fe de que, no solo en el contexto escolar, sino también en el familiar se estaban observando cambios muy positivos (RPE):

Ahora estamos muy contentos con el comienzo de la intervención con el método de comunicación alternativa PECS. Parece que está dando muy buenos resultados y, aquí en casa, los estamos viendo y lo utilizamos con ella también. Aunque aún no lo emplea para todas sus necesidades, poco a poco va incorporándolo más en su día a día y está mejorando mucho porque se hace entender (p. 2).

Para finalizar, de acuerdo con el objetivo principal del trabajo, es visible que no se han superado todas las limitaciones comunicativas pero, tras todo lo analizado, queda demostrado que se han conseguido grandes beneficios.

\section{Discusión}

Este trabajo pretende demostrar el efecto positivo que tiene el uso del sistema de comunicación por intercam- bio de imágenes en la comunicación de una niña con síndrome de West. La importancia de este hecho radica, principalmente, en los beneficios que ha aportado a la alumna en cuanto a las relaciones de interacción, petición y contacto visual, aspectos fundamentales para lograr la comunicación. Los análisis efectuados de los datos recabados así lo ratifican, pues se han contrastado las opiniones, recogidas en los diversos contextos en los que se desenvuelve el caso (los profesionales que trabajan con ella en el ámbito escolar y las personas de su entorno familiar), además del estudio de los registros de observación que se han llevado a cabo y de la documentación relacionada, que han ido encauzando esta investigación hasta alcanzar el objetivo propuesto.

Respecto a los resultados, señalamos que todos son positivos y muestran, no tanto que la intervención ha sido un éxito completo, sino que ha servido para provocar mejoras significativas en el desarrollo del caso y, principalmente, en la comunicación e interacción, los verdaderos objetivos de este trabajo.

Como se ha comentado desde un inicio, al realizar la propuesta de intervención, algunos profesionales se mantuvieron al margen e incluso se mostraron reticentes a su realización. Así pues, las evasivas de la tutora y la educadora se han plasmado también en sus respuestas (TICDIPT y TCDIE, respectivamente). Al proponer una intervención en su comunicación, ambas consideraron que la niña difícilmente respondería bien al sistema y que sus múltiples dificultades en cuanto a motricidad impedirían un buen desarrollo del método. Además, alegaban que la implantación de un sistema de comunicación alternativo mermaría sus habilidades lingüísticas e impediría que algún día desarrollara el habla. Estos pueden ser los motivos que, desde la triangulación, expliquen el desfase en cuanto a los resultados obtenidos; son distintas las valoraciones de los profesionales, porque también son dispares las concepciones iniciales que tenían, así como el escaso interés porque la propuesta fuera efectiva. 
Una vez introducido y llegado hasta la fase 3A, ellas mismas son conscientes de que sus juicios precipitados eran equivocados. En las propias observaciones que realizó la tutora en su test (TICDIPT: «ha mejorado muchísimo tras la intervención», «últimamente lo hace más») puede comprobarse cómo admite que los beneficios han sido evidentes y que se observan las mejoras día a día. Asimismo, en cuanto al habla, se han registrado (ROFIIM2804 y ROFIIM1205) producciones (/piii, mimi/ o el soplido) que al parecer la alumna dota de sentido (Peppa Pig, gusanitos, molinillo o pompero).

Por su parte, los resultados de la maestra AL (TICDIAL) así como del fisioterapeuta (TICDIF) son más positivos al tener una predisposición abierta y más optimista hacia la intervención, además de implicarse mucho más en la misma. En esta línea, cabe destacar que la respuesta de esta maestra es la más acertada y la que se adecua a la realidad, no porque sea la que mejores resultados muestra, sino porque los ítems que se estaban valorando tienen que ver, especialmente, con su campo de especialización. Es ella, pues, la persona idónea para evaluar y conocer las habilidades comunicativas, la socialización y la interacción de la niña, ya que su titulación así lo acredita.

Además se ha de añadir, a escala general, que las valoraciones que ha realizado cada uno de los profesionales son relativas, puesto que no pueden juzgar aspectos que no conocen. Consecuentemente, es probable que el fisioterapeuta no conozca tanto como la tutora el comportamiento de la niña en el grupo (ítem 31), al no tratarla en dicha circunstancia. Asimismo, la tutora no podrá saber, tanto como la maestra de AL, cómo se desenvuelve la niña ante un espejo si en la clase no disponen de dicho objeto.

En cuanto a los numerosos referentes en los que se ha apoyado esta investigación, pese a la escasa información del tema en concreto, cabe destacar que estos proporcionan una mayor consistencia a lo que aquí se ha tratado de demostrar, que no es otra cosa que la importancia de la intervención en la comunicación para conseguir que casos con ausencia de habla puedan disfrutar de la plena interacción con el mundo que les rodea.

Es evidente que, desgraciadamente, todavía existen numerosas personas en parecidas circunstancias, ante los que la escuela y la sociedad no están actuando todavía como sería conveniente. Es por ello por lo que este trabajo puede servir de referencia a todos aquellos que opten por utilizar este $u$ otro método con el fin de desarrollar las capacidades comunicativas en las personas, aunque tengan mínimas posibilidades de lograrlo.

Cabe añadir que a lo largo de la intervención han surgido obstáculos o limitaciones en nuestro trabajo. Por una parte, aquellos que se oponían al sistema dificultaban el desarrollo del mismo, tanto física como anímicamente. Presentar una propuesta que no es apoyada por el profesorado del centro y en la que apenas se confía merma en gran medida las posibilidades de trabajo, el interés y la actitud para llevarla a cabo, máxime cuando requiere de una gran coordinación. Por otra parte, las numerosas faltas de asistencia de la niña y las horas en las que permanecía dormida, sin que se le pudiera despertar por miedo a las crisis epilépticas, tampoco ayudaban para la continuidad y consistencia de la intervención.

Para finalizar, es importante destacar que, evidentemente, quedan muchas cosas por hacer en cuanto al propósito de la investigación. La más importante sería una continuidad del trabajo iniciado por parte de la maestra de AL y de la familia para poder lograr la consecución del resto de fases $y$, por tanto, una mejora en la calidad de vida de la niña. Además, el hecho de que, como se observa en los resultados, al comenzar con la primera fase del sistema el ritmo fuera bueno y rápidamente se consiguiera superar la siguiente puede apuntar a que, manteniendo este mismo ritmo de trabajo, pronto podría lograrse la superación de todas las fases. Pero para ello, cabe destacar, en esta misma línea que

Anexo 1. Items del Test Interacción y Comunicación

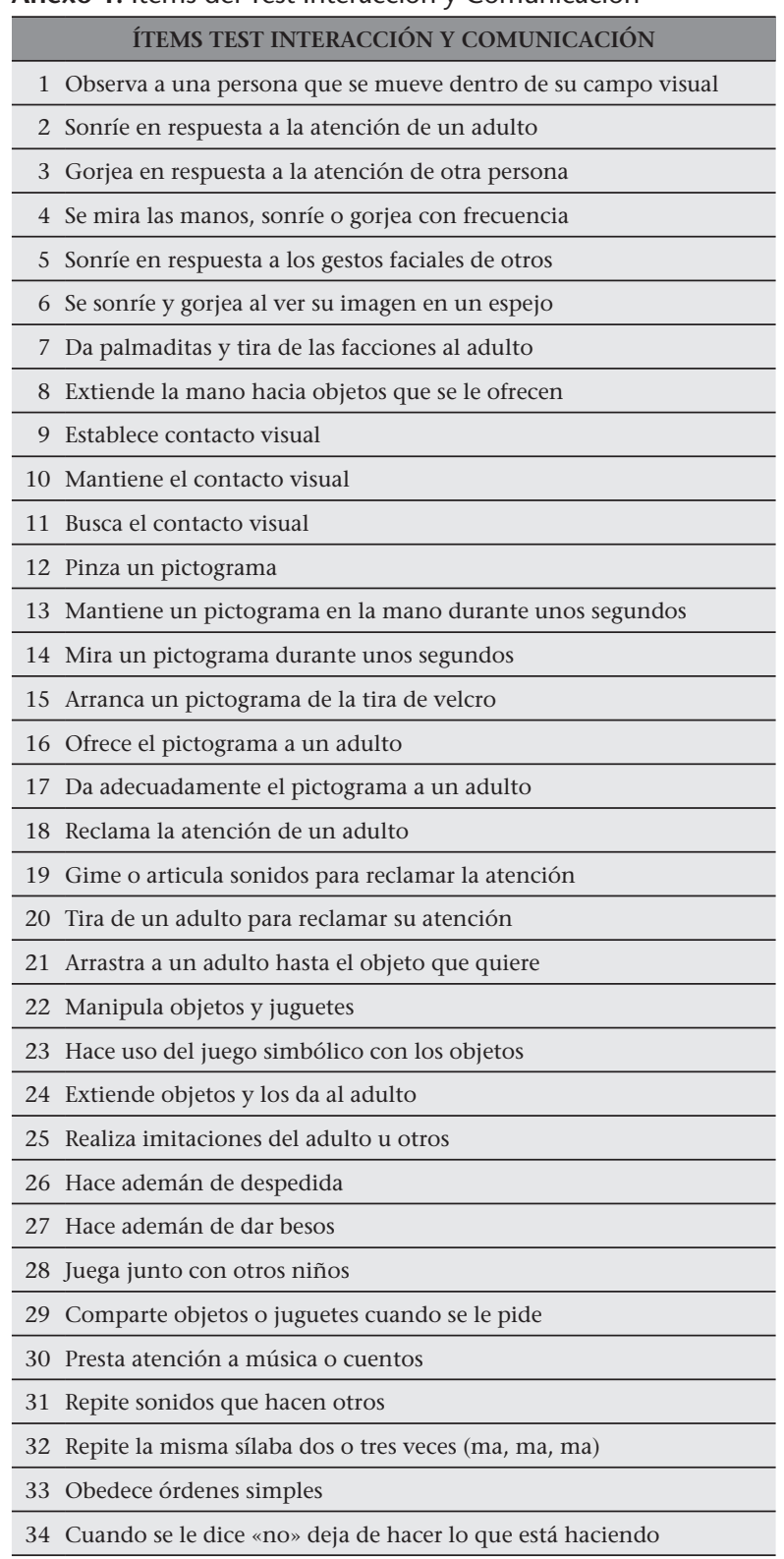


sería necesaria una generalización total del sistema en los distintos ámbitos; aunque para ello se requiere una aceptación del método por parte de todos los profesionales implicados. En definitiva, solo pretendemos dar un paso más hacia la igualdad de oportunidades en la atención a la diversidad. Ojalá todas las personas puedan disfrutar de la clave para el desarrollo humano: la comunicación (Crowder, 2003). De la que señalamos que, a diferencia de lo que consideran algunos, para comunicar no hace falta hablar.

\section{Glosario}

ITC: test inicial al caso de SW.

RPE: respuestas de los padres a la entrevista realizada.

ROFI1802: registro de observación en Fase I realizado el 18 de febrero (ejemplo).

TICDI: test de interacción y comunicación después de la intervención.

TICDIAL: respuesta del test de la maestra de Audición y Lenguaje.

TICDIPT: respuesta del test de la tutora / maestra de Pedagogía Terapéutica.

TICDIF: respuesta del test del fisioterapeuta.

TICDIE: respuesta del test de la educadora.

\section{Referencias}

Aguirre Barco, P., Angulo Domínguez, M. C., Guerrero Solana, E. Motero Vázquez, I., \& Prieto Díaz, I. (2008). Manual de atención al alumnado con necesidades específicas de apoyo educativo por padecer enfermedades raras y crónicas. Junta de Andalucía: Consejería de Educación.

Arberas, C. (2011). Actualización sobre la genética del autismo y la epilepsia. Ponencia presentada en el IV Congreso Internacional Fundación Síndrome de West: Nuevos avances en epilepsia pediátrica y autismo. Organizada por la Fundación Síndrome de West en Madrid.

Atuesta, A., Reina, D. C., Lozano, W. \& Gélvez, X. (2009). Síndrome de West: encefalopatía epiléptica. MedUIS, 22(1), 1-9.

Basil, C. (2001). Sistemas aumentativos y alternativos de comunicación. En J. Peña-Casanova, Manual de Logopedia (pp. 477-491). Barcelona: Masson.

Bluma, S., Shearer, M., Frohman, A., \& Hilliard, J. (1978). Guía Portage de Educación Preescolar. Lista de Objetivos. Barcelona: TEA.

Bolton, P. F., Carcani-Rathwell, I., Hutton, J., Goode, S., Howlin, P. \& Rutter, M. (2011). Epilepsy in autism: features and correlates. The British Journal of Psychiatry, 198(4), 289-294.

Calculator, S. (2004). Use of enhanced natural gestures to Foster interactions between children with Angelman síndrome. American Journal of Speech and Language Pathology, 11, 340-355.

Campistol, J., y García-Cazorla, A. (2003). Síndrome de West. Análisis, factores etiológicos y opciones terapéuticas. Revista de Neurología, 37(4), 345-352.
Chkout, C., Sarduy, C., Tunas, L. \& Leyva, C. (2011). Una concepción enriquecedora de atención educativa a los niños con diagnóstico del autismo y sordoceguera. Ciudad de La Habana: Educación Cubana.

Crowder, L. V. (2003). La comunicación: clave para el desarrollo humano. Managua: Representación de FAO en Nicaragua.

Díaz-Caneja, P. (2013). Atención temprana en el síndrome de Angelman. La importancia de la comunicación. Comunicación presentada en las X Jornadas de Atención Temprana de Andalucía. Sanlúcar de Barrameda. Marzo 2013.

Evertson, C. y Merlin, G. (2008). La observación como indagación y método. Métodos cuantitativos aplicados, 2, 174-188.

Forman et al. (2012). The need for worldwide policy and action plans for rare diseases. Acta Paediatrica, 101, 805-807. DOI:10.1111/j.1651-2227.2012. 02705.x

Frost, L. \& Bondy, A. (2002). The picture exchange communication system. Focus on Autism and Other Developmental Disabilities, 9(3), 1-19.

Fuentes-Biggi, J., Ferrari-Arroyo, M. J., Boada-Muñoz, L., Touriño-Aguilera, E., Artigas-Pallarés, J., Belinchón-Carmona, M. \& Posada-De la Paz, M. (2006). Guía de buena práctica para el tratamiento de los trastornos del espectro autista. Revista de Neurología, 43(7), 425-38.

Halle, J.W. (1984). Arranging the natural environment to occasion language. Seminars in Speech and Languaje, 5, 185-196.

Johnson, B. \& Onwnegbuzie, A. (2004). Mixed Methods Research: A Research Paradigm Whose Time Has Come. Educational Research, 33(7), 14-26.

Martin, G. \& Pear, J. (2008). Modificación de conducta. Qué es y cómo realizarla. Madrid: Prentice Hall.

Michael, J. (1983). Evocative and Repertoire-Altering Effects of an Environmental Event. Journal of the Analysis of Verbal Behavior, 2, 19-21.

Newborg, J. (2004). Inventario de desarrollo Battelle. Barcelona: Tea Ediciones.

Pacheco, E. \& Blanco, M. (2002). En busca de la "metodología mixta" entre un estudio de corte cualitativo y el seguimiento de una cohorte en una encuesta retrospectiva. Estudios Demográficos y Urbanos, 17, 3(51), 485-521.

Picture Exchange Communication System ${ }^{\circledR}$ (s.f.). ¿Qué es PECS? El Sistema de Comunicación por Intercambio de Imágenes. Recuperado de: http://go.uv.es/vRR0QYo

Pozo Alonso, A. J., Pozo Lauzán, D., y Pozo Alonso, D. (2002). Síndrome West: Etiología, Fisiopatología, Aspectos Clínicos y Pronósticos. Revista Cubana de Pediatría, 74(2), 151-161.

Sabino, C. A. (1989). El proceso de investigación. Santiago: El Cid.

Sampieri, R., Collado, C., Lucio, P. \& Pérez, M. (1998). Metodología de la investigación. México: McGraw-Hill.

Sansa, G., Carlson, C., Doyle, W., Weiner, H. L., Bluvstein, J., Barr, W. \& Devinsky, O. (2011). Medically 
refractory epilepsy in autism. Epilepsia, 52(6), 10711075.

Stake, R. E. (1998). Investigación con estudio de casos. Madrid: Ediciones Morata.

Toro Alonso, V. (2012). El juego en alumnos con necesidades educativas especiales: Síndrome de West y otras Encefalopatías Epilépticas (Tesis doctoral). Madrid: Universidad Complutense de Madrid.

Yin, R. K. (2003). Case study research: design and methods. Thousands Oaks, CA: Sage.

\section{Introducció del sistema PECS per a la superació de les limitacions comunicatives en un cas de síndrome de West}

Resum. En aquest estudi de cas s'aborda la intervenció realitzada en una alumna de quatre anys, escolaritzada en un aula específica d'un centre ordinari, $i$ a la qual han diagnosticat recentment sindrome de West. Aplicant, al llarg d'un trimestre en un aula d'Audició i Llenguatge, el sistema de comunicació per intercanvi d'imatges (PECS), es pretenen superar les greus limitacions comunicatives de l'alumna. El procediment metodològic utiltizat és mixt i les tècniques d'investigació emprades són l'aplicació de tests estandarditzats, l'entrevista, els qüestionaris, els registres d'observacions i l'anàlisi documental. A partir del test que estableix l'avaluació inicial del cas, s'aplica el programa i es registren diàriament les dades, a més d'entrevistar la família $i$ analitzar la documentació $i$ els qüestionaris complimentats pel professorat implicat. Els resultats obtinguts mostren que les reticències de part del professorat incideixen en la necessària coordinació, però no són cap obstacle perquè l'alumna assoleixi certs beneficis quant a les relacions d'interacció, petició i contacte visual, aspectes fonamentals per a aconseguir la comunicació.

Paraules clau: síndrome de West; sistema de comunicació alternatiu; PECS; intercanvi d'imatges; intervenció en comunicació 